\title{
Antecedents and consequences of the use of Facebook in learning contexts: a proposed framework
}

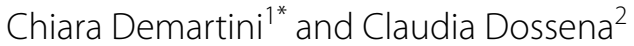

\author{
*Correspondence: \\ mariachiara.demartini@unipv.it \\ ${ }^{1}$ Department of Economics \\ and Management, University \\ of Pavia, Via San Felice, 5/7, \\ 27100 Pavia, Italy \\ Full list of author information \\ is available at the end of the \\ article
}

\begin{abstract}
Over the last decade business schools have increasingly changed their methods to deliver management and accounting courses. In particular, accounting education research is more and more devoted to the analysis of the use of technology, in particular social media, in educational settings. Nonetheless, there is a need for future research focussing on antecedents of the use of Facebook (FB) as a learning tool. Following an inductive approach, this exploratory study extends the literature on accounting education research. We used a participatory action research methodology and developed an online social network group for the students attending a management accounting class. From the empirical findings of this study, we identify the main determinants for the use of a course's FB group in a learning context, classifying them according to their role played in supporting social or learning processes. Finally, we suggest a preliminary model that is an educational adaptation of the unified theory of acceptance and use of technology (UTAUT) model.
\end{abstract}

Keywords: Learning, Accounting, Online social networks, Education, Participatory action research

\section{Background}

Over the last decade business schools have increasingly changed their methods to deliver management and accounting courses. Technological applications are increasingly strengthening their role in supporting learning for those students who perceive face-to-face learning as problematic for different reasons, such as the need to balance the time committed to work, education, and family (Millson and Wilemon 2008), or because it fails in fulfilling students' expectations on providing them with the core competencies for competing in the job market (Byrne et al. 2012). Specifically, accounting education research is more and more devoted to the analysis of the use of technology in educational settings. In this regard, more recent studies reported that both in- and out-of-class technology approaches enhance students learning (Edmonds and Edmonds 2010; Gaffney et al. 2010; Khanlarian et al. 2010; Lusher et al. 2012; Phillips and Johnson 2011; Premuroso et al. 2011). Since students are more and more familiar with technology, the use of technology in accounting courses should be strengthened, therefore "the challenge for academia is to stay abreast or ahead of student technology acceptance"

C 2016 Demartini and Dossena. This article is distributed under the terms of the Creative Commons Attribution 4.0 International License (http://creativecommons.org/licenses/by/4.0/), which permits unrestricted use, distribution, and reproduction in any medium, provided you give appropriate credit to the original author(s) and the source, provide a link to the Creative Commons license, and indicate if changes were made. 
(Apostolou et al. 2013). Furthermore, the use of online social media has been found to extend the potential of educational applications (Boon and Sinclair 2009), since it provides insightful educational opportunities for both students and teachers (Couros 2008). Prior research found that the use of FB as a learning tool can be explained by the user purposes (Mazman and Usluel 2010). Nonetheless, they stressed that future research should focus on antecedents of usefulness and relative advantage of FB as a learning tool.

Acknowledging the need for more research in this field, this study's main research question focuses on the investigation of the potential intervention factors linking the online social networking to the learning outcomes (Yu et al. 2010). We adopt an educational adaptation of the UTAUT model (Venkatesh et al. 2003). Many studies on e-learning adopt the UTAUT model for measuring students' acceptance of e-learning technologies (e.g., Marchewka et al. 2007; Chiu and Wang 2008; Jong and Wang 2009; Ismail 2010; Šumak et al. 2010). Anyway, to our best knowledge previous studies have focused their analyses on the acceptance level of e-learning tools only. Moreover, to our best knowledge previous studies have not applied the UTAUT model distinguishing between socialization and learning performances. Finally, the main determinants and consequences for the use of a course's FB group in a learning context remain still unexplored. Extending the UTAUT model (Venkatesh et al. 2003) to the use of a FB group for educational aims, we suggest an exploratory model that focuses on the determinants of FB group participation (independent variables) and relates them to FB performance for both socialization and learning purposes (dependent variables). Therefore, two research questions arise: What are the main determinants for the use of the online social networks in a learning context? What effects these determinants have on both social and learning outcomes? In order to effectively reply to these questions, we used a participatory action research methodology (Brydon-Miller and Maguire 2009) and developed an online social network group for the students attending a management accounting class, at the first year of a master programme.

In doing so, this study seeks to add new knowledge to the accounting education literature, since the use of technology in accounting courses has been found to foster learning, but the way in which technology improves students learning is still to be fully explored. This is more and more important from a societal and policy-making perspective, where the policy-makers should also take into account the return from the investment in technology and human capital to effectively implement technology in educational settings (Apostolou et al. 2010). Furthermore, the findings of this study would also enrich the literature on education of other academic disciplines, specifically, but not only related to, business and management courses.

\section{The use of $\mathrm{FB}$ in learning and socialization processes}

Like most online social networking sites, FB is used to maintain existing and develop new networks (e.g., Ellison et al. 2007): FB is mainly seen as a mean to maintain and develop students' social capital, i.e., make new friends at University, keep in touch with friends and family at home, and only rarely with University staff (e.g., Madge et al. 2009). At University, FB was part of the "social glue" that helps students integrate into University life (Madge et al. 2009). Education literature stressed that the use of social networks is more related to the social than the learning dimension of the tool (Baran 2010). 
However, it can be used also for learning purposes. Research has suggested that FB is a potentially useful tool for promoting effective academic practice. Kosik (2007), for example, found that some students use FB for academic purposes, in particular to contact other student to get information about assignments. The author also found that students prefer $\mathrm{FB}$ to the university education software programme (traditional e-learning tools) because it provided more immediate responses. Mason (2006) suggests its utility lays in its reflective qualities, its mechanisms of peer feedback and its collaborative models of learning. Selywn (2007) notes its attractiveness resides in its ease of education related interactions between students, although often in an informal way (i.e., for student-tostudent interactions about academic work-related issues). In this way, FB stimulates collaborative student-led learning. FB can be also a useful tool also for formal learning processes (Bosch 2009): FB has made learning contents much more freely and instantaneously available to students who can easily download course notes and readings. Some researches, for example, have explored how students feel about having lecturers on FB (e.g., Hewitt and Forte 2006) and how faculty participation affects student-professor relations (Mazer et al. 2009).

However, FB may also have a negative impact on learning performance, since it could be also a distraction for students (Bugeja 2006). However, if one considers the large numbers of students on FB often actively participating in discussions and groups, it cannot be ignored as a potential educational tool. Bosch (2009) argues that, compared to university course sites, students are more engaged with $\mathrm{FB}$, and perhaps educators need to explore new ways to develop closer relationships with their students.

\section{Accounting education and online and social networking learning}

The use of online or social media learning in accounting courses is one of the most researched topics in accounting education literature (Apostolou et al. 2010, 2013). Both in- and out-of-class technology-based delivery methods have been analyzed. Among the studies on the in-class online delivery systems, the use of a synchronous chat room in a distance education executive MBA programme provided enhanced performance compared to an asynchronous participation to an online discussion board (Duncan et al. 2012). In-class online learning delivery methods can provide other than learning performance outcomes. In fact, digital storytelling has been found to produce better results in terms of student engagement, compared to written alone word. Suwardy et al. (2013), in fact, developed a 12 episodes digital story to help student understanding the role of accounting in decision-making activities. From the out-of-class perspective, Gaffney et al. (2010) found that the use of an online homework management system significantly improved the students' performance related to some types of assessment. Similarly, Phillips and Johnson (2011) conducted a comparison between an online homework system and an online intelligent tutoring system, which resulted in better performance for those students using the intelligent tutoring system. Out-of-class online technology can improve student motivation and engagement as for the in-class approach. Results from the study by Sargent et al. (2011) demonstrated that student motivation to accounting courses was higher for those students watching extra-short online tutorials. Moreover, enhanced student motivation resulted in higher score performance (Sargent et al. 2011). Accordingly, a study on the use of Second Life ${ }^{\mathrm{TM}}$ provided evidence that student 
engagement through online social media produced improved learning performance, since the time spent by students in Second Life ${ }^{\mathrm{TM}}$ was positively correlated with the score at the final test of an introductory accounting class (Hornik and Thornburg 2010). Another relevant issue in online learning studies is the way in which students interact through the technological learning tool. According to the findings by Wells et al. (2008), students of a second-year accounting class prefer a one-way communication, mainly related to the online access to course notes and announcements, when using virtual learning environment, compared to a two-way interaction with other students. Other studies addressed prior subject knowledge and the amount of time spent on the online learning tool as drivers of learning performance, although results on the student's attitude toward the online learning system were mixed (Marriott et al. 2004; Potter and Johnston 2006).

From the reviewed literature on accounting education and online or social networking learning, we can argue that prior studies addressed motivation to learn, student's engagement in the taught discipline and prior subject knowledge as the main drivers of the use of technology for enhanced learning outcomes. To our best knowledge, no other accounting education study has been undertaken to investigate on the determinants of the use of online social networking for learning purposes in the accounting field.

Although the use of technology in accounting education is promising in terms of enhanced student engagement, satisfaction and performance, it is worth noting that teachers should be aware that not all technology-based approaches result in improved performance. In fact, only an effective implementation and use of the online technology will produce successful performance (Jones and Wright 2010). For this reason, it is important to identify the determinants driving an effective use of the technology by both students and teachers for learning purposes.

\section{Application of UTAUT model in e-learning processes}

In this work, we suggest that the UTAUT model (Venkatesh et al. 2003) can be used to analyze international students' acceptance on using the social networking site to support their learning activities.

The model postulates the constructs of performance expectancy, effort expectancy, social influence, and facilitating conditions on using technology. These constructs determine the behavioral intent, which influences the usage behavior of the technology.

Performance expectancy is defined as the degree to which the students believe that using social networks will help support their learning activities.

Effort expectancy is defined as the degree of ease associated with the use of social networks.

Social influence is defined as the degree to which a student perceive that it is important for others to believe that he or she should use the social network. This variable is important in the early stages of experience with technology, with the effect diminishing over time.

Finally, facilitating conditions represent the organizational support (academic support), which include the constructs of perceived behavioral control, facilitating conditions, and compatibility with other platforms of technology. 
All these constructs and their relationships are mediated by experience in social networks, gender, age, and voluntariness of use these tools.

Many studies on e-learning adopt the UTAUT model for measuring students' acceptance of e-learning technologies (e.g., Marchewka et al. 2007; Chiu and Wang 2008; Jong and Wang 2009; Ismail 2010; Šumak et al. 2010). Jong and Wang (2009) modified UTAUT (Venkatesh et al. 2003) to determine technology acceptance of web-based learning system of Taiwan technical university students. They found that performance expectancy, attitude toward using technology, facilitating conditions, self-efficacy, and social influence have significant influence on behavior intention. Moreover, only behavior intention, attitude toward using technology, and social influence have direct impact on system usage.

Particularly interesting for our research purposes is the work of Ismail (2010), that focused on the role of social networks to support knowledge activities of international students. The author found that social networks are able to bridge the cultural gap and build trust among students and members of the faculty. They are also useful platform for knowledge sharing when the students start to accept that the interaction among members within the site could support their learning activities. The results show that the international students agreed on the idea that the performance expectancy, effort expectancy, social influence, and facilitating conditions will lift the behavioral intention of using social networks to support their learning activities.

Ismail's work emphasizes the dual role of social networks: they can be seen both as socializing tools and as learning tools. But can they play this dual role also among students that have not cultural differences? This works aims at giving a preliminary contribution about the role that FB can have in supporting both socialization and learning processes among students of an Italian university.

\section{Context of analysis, data, and methodology}

This study is aimed at understanding the logics of the use of FB in a management accounting master class and its impact on social and learning outcomes. Table 1 highlights the descriptive statistics of the surveyed sample.

Since the analysis of which determinants affects the use of a FB group for both learning and socializing purposes is not fully explored in the related literature (Apostolou et al. 2010), this study develops a participatory action research methodology (Brydon-Miller and Maguire 2009; Greenwood and Levin 1998). At the base of participatory action

Table 1 Descriptive statistics of the surveyed sample

\begin{tabular}{lllll}
\hline & Mean & Min & Max & Number \\
\hline Age & 23 & 22 & 24 & 9 \\
$\begin{array}{l}\text { Background } \\
\text { Communication studies }\end{array}$ & & & 6 \\
Italian studies & & & 1 \\
Law & & & 1 \\
Other/no specification & & & 110 with honor & 8 \\
Bachelor score & $102.13 / 110$ & $90 / 110$ & & 1 \\
\hline
\end{tabular}


research is the assumption that knowledge is always created in the context of human relationships (Maguire 2001). Thus, features of participative action research in educational studies include, among others, (1) the active role of the researchers/teachers in the study, who deepen the relationship with students in order to build trust and identify actual problems and actions to be taken to solve them, (2) the involvement of students as co-researchers, who feel they are legitimatized to express their opinion and play a significant role in governing the change in their student's life quality, (3) and the commitment to substantially change students' life by improving students' learning experience. This study is specifically aimed at filling the gap of research activity in projects designed for acting with young people's perspectives (Groundwater-Smith and Downes 1999). In fact, the inclusion of students in the FB group and the collection of student's opinions on their experience in face-to-face and online learning is specifically designed to gather students' perception on their students' life. Furthermore, data gathering adopts a comprehensive approach, since students can provide their viewpoints on the FB project through both interviews and a survey with open-ended questions.

The research setting is the online FB group developed specifically for an Italian master class in management accounting, which has been chosen for the present study. In this group, the teacher has the role of administrator and supervisor, whereas students ask to join the group to the administrator and actively use the online social group. Students became aware of the existence of the social group either from the teacher or from other students who had already joined the group. The period of analysis started in September 2012 and finished in February 2013. The total number of students engaged in the FB group is 12 . The management of the group is aimed at fostering supplementary materials to the course syllabus together with information related to the organization of the class, tutorials, and other relevant information on the final test. Supplementary materials are provided in order to foster the students' interest and motivation toward the discipline. Starting from this assumption, the teacher added on the FB group wall some magazine articles links and other website links discussing topics already discussed or planned to be explained in subsequent lectures. Students could also make questions and add further information on the group wall in order to get and share knowledge on the course topics and the discipline in general.

Evidence in this study comes from semi-structured interviews and a survey with openended questions administered to the students who participated to this study, through an online questionnaire tool. In-depth interviews lasted approximately $45 \mathrm{~min}$. Interviews have not been tape-recorded in order to give more confidentiality to the contents of the interview, thus reducing any respondent bias in the interviewees. In order to reduce the recording error, which is related to the mistakes that the interviewer can make taking notes, another researcher was involved in the interview with the role of transcribing verbatim of the exact words of the interviewees' answers, without any summary or paraphrasing (Fowler and Mangione 1990). The adjunct researcher also took notes of the interviewees' behavior during the interview, which added further knowledge to the data collected during interviews. The interviewer and the adjunct researcher discussed over the notes taken during the interview at the end of the same interview, in order to effectively code and analyze data, which was just collected. Interviews were conducted through open-ended questions in order to enhance the interviewee's perception of her/ 
his active role in the dialog with the interviewer (Denzin and Lincoln 2005; Ghauri 2004). Four students undertook the in-depth interview. Three of them joined the FB group, whereas the other one decided not to join the group. The choice of the interviewees reflected the proportion of students in the management accounting class who joined/not joined the group. In fact, the class was composed of 16 students, among which 12 joined the FB group.

At the end of the course, an online questionnaire has been administered to both students joining the group and those ones who decided not to join the FB group. The open-ended questions enriched the informational power of data gathered from a static research tool (Geer 1988, 1991), such as a questionnaire, in order to get further insights into specific issues of expectations, determinants, and effectiveness of the use of FB as an online learning tool. We collected 9 questionnaires from both students engaged in the FB group and those who did not. The response rate is $56.25 \%$ and the data collected from the open-ended inquiries are valuable for the interpretation of data gathered through the interviews.

\section{Results and discussion}

From the interviews and the questionnaires, we collected a rich amount of data that we used to show results of our study and develop discussion. In this study, we aimed at developing a theoretical framework for assessing the main factors affecting the perceived socializing and learning effectiveness of an online social network group developed for a post-graduate course.

In order to extend prior knowledge on this topic, we adapted the integrated model UTAUT (Fig. 1). Extending the UTAUT model (Venkatesh et al. 2003) to the use of a FB group for educational aims, we suggest an exploratory model that focuses on the determinants of FB group participation (independent variables) and relates them to FB performance for both socialization and learning purposes (dependent variables). In the original UTAUT model, moderating variables are taken into account, i.e., gender, age, experience, and voluntariness of use. In our model, the first three moderating variables are excluded because the experience, which is related to the educational background, is similar in the surveyed sample. Moreover, the range of the age of the surveyed sample doesn't vary much. Moreover, all the students of the sample are females. Therefore, for the sample characteristics and the purposes of this research design, these three variables are less relevant and, thus, excluded from our analysis. With regard to the voluntariness of using the FB group, its significant importance for our research question leads us to insert it in the main determinants of FB group participation. Therefore, we consider the voluntariness of using the FB group as a component of the independent variable motivation to use FB as a socializing and a learning tool.

\section{Facebook as a socializing tool}

As for the socializing determinants, the following are the main drivers of the students' perceived effectiveness in terms of socialization outcomes (Fig. 1). 


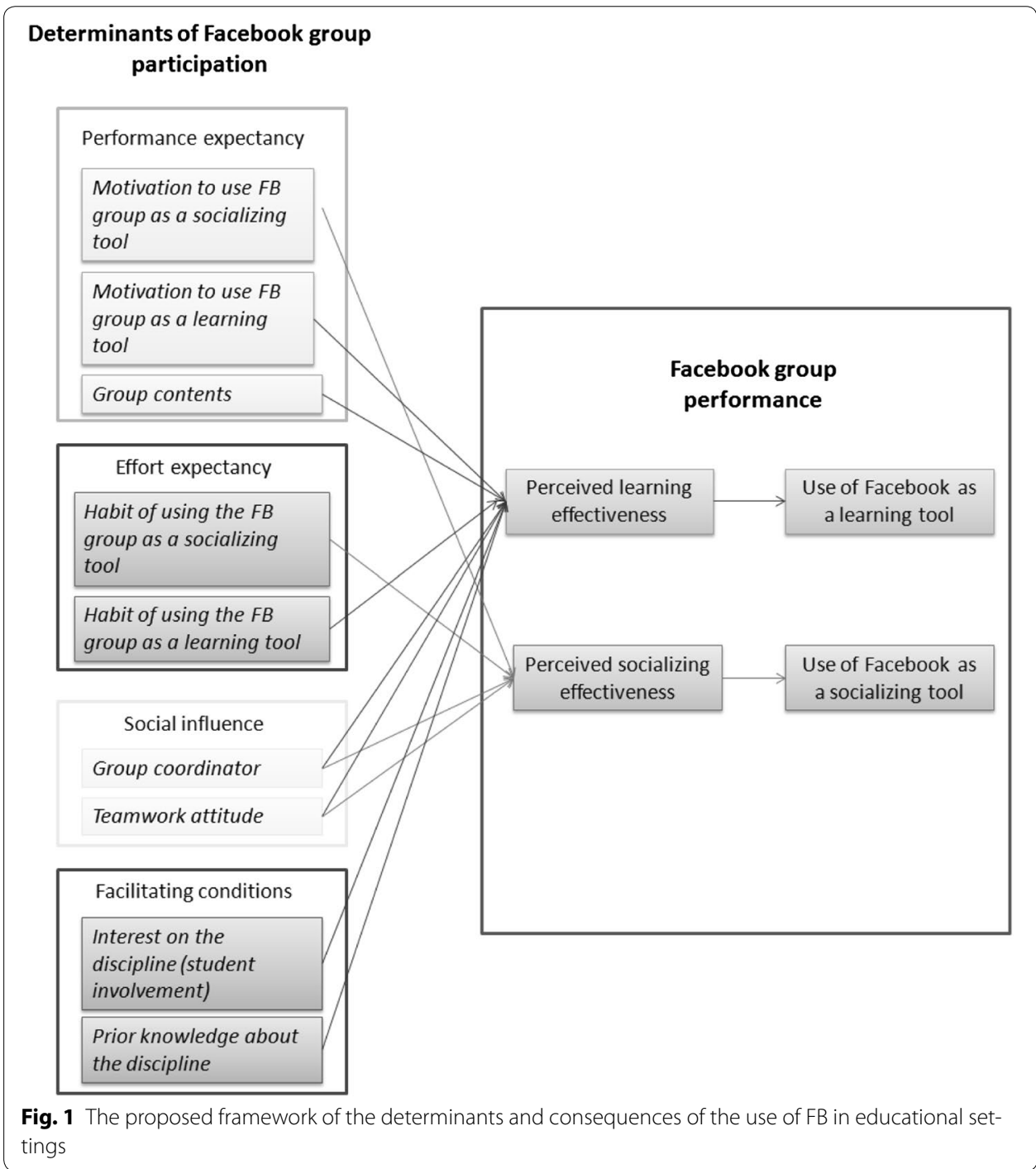

\section{Motivation to use FB group as a socializing tool}

In line with previous literature (Ellison et al. 2007; Madge et al. 2009; Baran 2010), our study pointed out that the motivation to use FB as a socializing tool predicts the use students do of the online social network, i.e., to have fun and chat with other people. Students stated that they use FB as a way to have fun and chat with other friends, as well as to share their hobbies and the fan pages they joined to on their personal page on the FB. Contrary to expectations and to some previous works (Ellison et al. 2007; Madge et al. 2009), students stated that they generally do not use FB as a way to get in touch with new friends, though the course's FB group was used as a way to meet new people in the same class.

Similar results from other studies highlighted that the FB is very important in helping students to form friendship at university, especially for mature forms of communication (Madge et al. 2009). Prior studies addressed the relational capital as a key factor in building entrepreneurial teams (Adler and Kim 2007) and leadership success (Balkundi and 
Kilduff 2006). Moreover, the study contributed to build proximity between classmates, which has been found to contribute to information seeking and knowledge sharing in social relations (Borgatti and Cross 2003), and in online social network too (Wang et al. 2012). Nonetheless, there was also a resistance to engage on the FB from some of the interviewed students, since they argued that FB can be addictive and messages overwhelming their private life. According to this perspective, nonparticipants can be classified as 'conscientious objectors', i.e., those people politically minded protesting against the social network, or those students who feel they are too clever for these sites (Boyd 2008).

\section{Group coordinator}

Contrary to expectations, but in line with prior studies, students perceived the presence of the teacher within the online social network group as a limiting factor for socializing, since they felt under control and reduced their online interaction within the group in order not to feel assessed by the coordinator in posting their messages to the group page.

\section{Teamwork attitude}

Although the interviewed students did not show a teamwork attitude, since they are not used to studying with other mates, they perceived as important to join the course group on the FB. The teamwork attitude is a key factor in supporting the use of FB as a socializing tool. The organizational demography literature, in fact, stressed that group performance may depend upon either the demographic characteristics of prospective team members or the social network to which they belong to (see e.g., Williams and O'Reilly 1998). In this sense, a social network will share most of the characteristics of its members and the members' features will be very similar. Thus, sharing a high attitude toward teamwork within classmates will significantly affect the course group performance on the online social network in terms of socialization, since members will be keener to share personal traits and build up strong ties. However, homogeneity in members' characteristics does not mean that there could not be any differences between group members, in fact, prior research put forward that expertise diversity is a positive driver in group performance (Van der Vegt and Bunderson 2005).

\section{Habit of using the FB group as a socializing tool}

From questionnaires students stated that they became more and more familiar with FB groups whose topics are related to their life at university and bureaucratic and content matters related to the courses they have to attend.

Moreover, students argued that the course's FB group is an alternative way of keeping in touch with their mates and the teacher even after the end of the class.

Students who joined the group perceive a closer relationship between each other. They think this relationship would help them in finding suitable solutions to problems, which could arise in the future.

The habit of using FB for socialization purposes significantly affects the related effort expectancy in using it. Results from this study support the empirical findings of prior literature on the FB as a social networking and social capital tool (Ellison et al. 2007; Kosik 2007; Neibling 2010). In particular, our study contributed to the strand of literature that 
explored the FB as a method for developing 'maintained social capital', i.e., the ability to stay in touch with members of a community of which the individual is member (Ellison et al. 2007), since the students pointed out that the FB contributed to build relationship which could be fruitful for the future of their university life. In fact, students who joined this study declared that they are keen to link to university groups on the FB in order to pursue other than learning objectives and improve their experience at university. At a general level of analysis of the students' experience in their university life, some researchers found that there is a gap between students' expectations and their perception of the reality they experience at university (Cheong Cheng and Ming Tam 1997; McInnis et al. 2000; Sander et al. 2000). The student-environment fit has been addressed as a relevant issue in terms of student retention (McInnis et al. 2000). Whenever students feel they are part of the community in their university life, they are more likely to successfully complete the programme. On the other hand, when they perceive a distance from the group, they are more dissatisfied and decide to leave university (Tinto and Love 1995). In our study, students declared they used the FB group to link with new students, attending the same class, whom they did not meet before, and this improved their university experience, since they perceived that this social network would have been useful to solve future problems that could arise in their university life. These results are in line with the study by Ryan et al. (2011) who analyzed how relational ties on the FB helped $\mathrm{PhD}$ students to get involved in a PhD program abroad. This is also the case for the student-lecturer relationship, since students stated they positively valued the availability of a FB group for the class they attended; in fact they viewed the lecturer involved in a FB group as more open toward their students, compared to other lecturers. Prior studies identified being approachable as one of the key characteristics students addressed for a good lecturer, together with teaching skills, teaching methods, communication skills, enthusiasm, expertise, humor, and friendliness (Voss et al. 2007).

\section{Facebook as a learning tool}

In our model, we suggest that the perceived learning effectiveness depends upon the students' use of FB group as a learning tool (Fig. 1). Unlike typical online socialization companies' groupthink (such as MySpace.com), FB is purposely designed as a tool for people to communicate, get information, and share information (Locke 2007).

Even if FB is not a traditional e-learning platform, we suggest that it could be a useful tool in supporting both socialization and learning processes.

As for the learning determinants, the main drivers of the students' perceived effectiveness are the following:

\section{Interest on the discipline (student involvement)}

Astin (1984) says that education activities should be evaluated in terms of their ability to induce greater student involvement. Many authors (e.g., Rodgers 2008; Mason 2011) argue that e-learning can be a way to increase student involvement. But can FB increase student involvement on the discipline? FB offers opportunities for extracurricular activities, peer group interactions, social integration, and faculty-staff interactions. Involvement with FB may help or hinder a student's academic performance and integration (Heiberger and Harper 2008). 
Surely the playful aspect of FB and its socialization aim effectively support student involvement. In our study, we found that student involvement in a discipline increase also its proneness to approach to the FB group as a tool to improve their knowledge. Obviously, the moderator, as group coordinator, has a fundamental role in supporting student engagement on the discipline.

\section{Group contents}

The typology of contents shared within the FB group significantly affects the FB effectiveness for learning purposes. From this point of view, we can have at least three different typologies:

- contents aimed at increasing socialization among the community members;

- contents aimed at supporting learning process and strictly linked to the course topics;

- contents aimed at supporting learning process and loosely coupled to the course topics.

Students perceive as more useful contents shared in the FB group that are not covered at lesson but that are related to them, such as insights, news, and real exercises.

Each kind of content can be generated by both the group coordinator (teacher) and students and can have a playful as well as a "useful" aim. The playful aim refers to an individual's tendency to interact spontaneously, inventively, and imaginatively with computers (Webster and Martocchio 1992) and it is strictly related to the users' satisfaction (Woszczynski et al. 2002; Lin and Tsai 2005; Roca et al. 2006). Woszczynski et al. (2002) developed a theoretical model of playfulness in computer interactions. They suggested that user satisfaction might be a consequence of the playful behavior, and that moresatisfied users will tend to continue to behave more playfully in their computer interactions. The useful aim is strictly related to the motivation to use FB as a learning tool.

\section{Motivation to use Facebook as a learning tool}

The motivation to use FB as a learning tool is the main determinant in the use of FB as a learning tool; as previously said, students can be motivated in using it by both intrinsic and extrinsic incentives. By integrating a motivational perspective into the technology acceptance model, Lee, Cheung, and Chen (2003) developed a model that captured both extrinsic (perceived usefulness and ease of use) and intrinsic (perceived enjoyment) motivators for explaining students' intention to use Internet as a learning medium. In their work they found that perceived ease of use did not posit a relevant impact on student intention to use Internet as a learning tool. In our study, we found that perceived usefulness of the FB group is the main determinant for every student inscribed to the group. All the students believe that taking part in the course's FB group can help them to increase their knowledge. In particular, they declared they expected to find in the group specific insights, additional exercises, and additional information about the course and the exam.

Accordingly to Lee et al's results (Lee et al. 2005), perceived ease of use is irrelevant in the choice to participate in the course's FB group. 


\section{Group coordinator}

The moderator has a fundamental role in learning process: the group coordinator edits contents, stimulates, and moderates the discussions, and proposes contests, tests, and so on. The typology of moderation process influences also the main aims that students recognize at the FB group (socialization vs learning). The moderation style significantly influences the users' attitude within an online community (Pedersen 2008). In our study, we found that the group coordinator (the teacher) has not impacts on learning performance even if it significantly impacts on the active or passive attitude adopted by students.

\section{Teamwork attitude}

Knowledge sharing is fundamental to learning among students and has a very important social component (Uden and Eardley 2011). The perception of learning as a social process is widely studied in literature especially on communities of practice (Wenger 1998, 2000) and collaborative learning (e.g., Dillenbourg 1999). From this point of view, we perceived the learning process with both a top-down approach, when knowledge flows from teacher to students, and a more bottom-up approach, such as in collaborative learning, when students learn from each others.

In our study, we found that students that have higher teamwork attitude (i.e., creating study groups offline) are also more likely to perceive FB as a learning tool because they recognize knowledge sharing as a fundamental component in the learning process.

\section{Habit of using the FB group as a learning tool}

Although FB has been in existence only since 2004, student involvement along this continuum has increased exponentially (Heiberger and Harper 2008). As previously said, the familiarity in using FB increases both its usage as a learning tool and as a communication and socialization tool. One study shows students spending an average of one to two hours a day on FB and logging in an average of three times per day (Heiberger and Harper 2008). Recent data from the Higher Education Research Institute (2007) also show that $94 \%$ of students use social networks in a typical week and approximately $60 \%$ of them spend from one to five hours per week. In our study, only three students (out of eleven) have not a FB account and approximately $70 \%$ of students with a FB account spend from one to five hours per week. We can distinguish between students that rarely use FB (i.e., less than $4 \mathrm{~h}$ a week) that represent about an half of our sample, and the other $50 \%$ of the sample, which has students that use more frequently FB (i.e., between 5 and $14 \mathrm{~h}$ a day). An interesting result is that people that spend more time in FB are also those who mainly perceive the informative role of the group in supporting learning processes. On the contrary, people that spend less time in FB highlight mainly the socialization role of the group.

\section{Prior knowledge about the discipline}

In our sample, only one-third of the students have previously studied, at the high school or at university, topics similar or related to the course. However, even if most of them are not familiar with the course's topics, all the students declared they are very interested in. Notably, students that have prior knowledge about the course topics (i.e., economic and 
business knowledge developed in previous courses) are also more likely to participate at the FB group for learning purposes. This result is consistent with our assumption that having prior knowledge about the discipline is related to the student involvement.

Even if actually data cannot allow any generalization, we suppose that students that are more familiar with the topics of discussion are also more likely to actively participate at the FB group (i.e., editing posts and comments).

\section{Socializing and learning performance of FB group}

A fundamental issue is how to measure learning performance in a course's FB group? There are many proxies that we could use: examination results, the student's participation in the group activities, and the student satisfaction. According to the UTAUT model, the latter is very important in e-leaning contexts and for our research aims. Therefore, we have focused mainly on this performance indicator.

In our study, we considered two aspects related to the performance of $\mathrm{FB}$ group (Fig. 1). As amply argued in the literature on education and social media, FB has two main aims: a socializing and a learning purpose. Therefore, we focus on both socializing and learning performance related to the FB group. In particular, because of our interest in behavioral intention to use the FB group, we focus on students' perception of FB group in satisfying both socialization and learning purposes.

Socializing is one of the dependent variables of the proposed framework. In this study, we developed a FB group for a master course in order to assess its performance in terms of socialization. Traditional literature on the online social networks stressed the importance of socializing as a key purpose of social networks, such as FB (Aydin 2012; Pempek et al. 2009; Subrahmanyam et al. 2008). Both individual and group levels of analysis have been considered in this study. At the individual level, socializing performance dimensions relate to student-student interactions and student-teacher ties. Indeed in our study, as in other research (Baran 2010), socialization has been conceived as an important factor in order to build individual identity within a class group. In this sense, the class group contributed to develop what Van der Vegt and Bunderson (2005) defined as 'collective team identification,' which reflects the "emotional significance that members of a given group attach to their membership in that group" (p. 533). Students pointed out that through the participation to the FB group they developed relational capital in both their relationships between students and with the teacher. From the results retrieved in our study, student-student interactions were addressed as the most important achievement they gained through the FB group. Since most of the students were at the first year of their master degree, they did not know each other and the group facilitated the development of social capital. On the relational capital side, students also referred that the participation to the FB group stimulated their willingness in performing teamwork aimed at creating and developing social relations for both learning and non-learning purposes.

From the student-teacher interaction, results are mixed. On the one hand students perceived as good the teacher involvement in the FB group, they perceived the studentteacher gap as looser and addressed the FB group as an opportunity to improve their university experience. On the other hand, they felt it as an incumbent presence. This result could be due to the fact that the class size was quite small and the number of 
students involved in the project was also relatively low. At the collective level of analysis, socializing performance refers to the effectiveness of the group in building fruitful relations. Students involved in this study referred that their participation to the class group improved their way of communicating and sharing information online (on the FB) and offline. Negative features related to the use of the FB group emerged too. Some students reported a perception of poor privacy in joining the $\mathrm{FB}$, so they preferred not to join the FB but getting in touch with their mates in different ways.

Overall, it could be said that the FB group can be conceived as an enabling factor for socialization performance, especially for those who had fewer relationships before joining the group. In fact, among those students who have a FB profile, more than a half stated that they had less than three friends-among their mates-on the FB before joining the group, while they increased of at least of three people the number of friends after joining the group. On the other hand, those who had at least three mates as friends on the FB before joining the group had a poorer socializing performance after joining the group.

The perceived learning effectiveness is our second dependent variable. With the progress of ICT development and the diffusion of social media, e-learning is emerging as the paradigm of modern education. The main advantages of e-learning include liberating interactions between students and teachers from limitations of time and space through the asynchronous and synchronous learning network model (Trentin 1997; Katz 2000, 2002) and collaborative learning through a structure many-to-many. The e-learning market has a growth rate of $35.6 \%$, but there are many cases in which e-learning fails (Arbaugh and Duray 2002; Wu et al. 2006), mostly because users stop their online learning after their initial experience. In our sample, in general, students perceive as important to be part of the FB group. In particular, they appreciate especially the informative role of FB in giving information about the course and the exam (mean: 5.29; standard deviation: 0.76). Less strong, but still important, is the perception of FB group in supporting learning processes, even if data are not so clear (mean: 5 ; standard deviation: 1 ).

Anyway, some students declared they do not want to join to the FB in order to avoid overexposure to the messages that their FB network sends them.

\section{Conclusion}

Adopting a pragmatic approach, this study aims at investigating the potential intervention factors linking the online social networking to the learning outcomes ( $\mathrm{Yu}$ et al. 2010). In particular, we focus on accounting education, an interesting research field that, to our best knowledge, needs a deeper investigation on the determinants of the use of online social networking for learning purposes.

In this study, we focus on a well-known social network: Facebook.com. By adopting an educational adaptation of the UTAUT Model (Venkatesh et al. 2003), this exploratory paper aims at giving some preliminary suggestions related to the identification of the main determinants for the use of the online social networks in a learning context and the analysis of the effects these determinants have on both social and learning outcomes. In order to satisfy our research interests, we used a participatory action research methodology (Brydon-Miller and Maguire 2009) and developed an online social network group for the students attending a management accounting class, at the first year of a master programme. 
From the empirical findings of the study on the class we studied we suggest a preliminary model that identifies the main determinants for the use of a course's FB group in a learning context, classifying them according to their role played in supporting social or learning processes.

We are aware of the limits of the study, first of all, due to the small sample and the focus on a class (a master degree course), that cannot allow us to make any generalization. However, we believe that this contribution, even if exploratory, could also enrich the literature on education of other academic disciplines, specifically, but not only related to, business and management courses. In future research, we would apply and test our model in other contexts and courses. In particular, it could be interesting to apply the model in universities of different countries in order to assess the different perspectives that students can have in the adoption of social networks for formal and informal learning processes.

Abbreviation

FB: Facebook.

Author details

${ }^{1}$ Department of Economics and Management, University of Pavia, Via San Felice, 5/7, 27100 Pavia, Italy. ${ }^{2}$ Università Cattolica, Milan, Italy.

Competing interests

The authors declare that they have no competing interests.

Received: 30 May 2015 Accepted: 6 April 2016

Published online: 10 May 2016

\section{References}

Apostolou B, Hassell JM, Rebele JE, Watson SF (2010) Accounting education literature review (2006-2009). J Account Educ 28(3):145-197

Apostolou B, Dorminey JW, Hassell JM, Watson SF (2013) Accounting education literature review (2010-2012). J Account Educ 31(2):107-161

Arbaugh JB, Duray R (2002) Technological and structural characteristics, student learning and satisfaction with webbased courses: an exploratory study of two online MBA programs. Manag Learn 33(3):331-347

Astin AW (1984) Student involvement: a developmental theory for higher education. J Coll Stud Pers 25:297-308

Aydin S (2012) A review of research on Facebook as an educational environment. Educ Technol Res Dev 60(6):1093-1106

Balkundi P, Kilduff M (2006) The ties that lead: a social network approach to leadership. Leadersh Q 17(4):419-439

Baran B (2010) Facebook as a formal instructional environment. Br J Educ Technol 41(6):E146-E149

Boon S, Sinclair C (2009) A world I don't inhabit: disquiet and identity in second life and Facebook. Educ Media Int 46(2):99-110

Borgatti SP, Cross R (2003) A relational view of information seeking and learning in social networks. Manag Sci 49(4):432-445

Bosch TE (2009) Using online social networking for teaching and learning: Facebook use at the University of Cape Town. Communication 35(2):185-200

Boyd D (2008) Can social network sites enable political action. Int J Media Cult Politics 4(2):241-244

Brydon-Miller M, Maguire P (2009) Participatory action research: contributions to the development of practitioner inquiry in education. Educ Action Res 17(1):79-93

Bugeja MJ (2006) Facing the Facebook. Chronicle of Higher Education, January 23, from http://chronicle.com/ jobs/2006/01/2006012301c.htm. Accessed 1 Feb 2013

Byrne M, Flood B, Shanahan D (2012) A qualitative exploration of oral communication apprehension. Accout Educ 21(6):565-581

Cheong Cheng Y, Ming Tam W (1997) Multi-models of quality in education. Qual Assur Educ 5(1):22-31

Chiu CM, Wang ETG (2008) Understanding web-based learning continuance intention: the role of subjective task value. Inform Manag 45(3):194-201

Couros A (2008) Safety and social networking: how can we maximize the learning power of participatory web sites while ensuring students are protected and behave responsibly? Technol Learn. 28(7):20-23

Denzin NK, Lincoln YS (eds) (2005) The Sage handbook of qualitative research. Sage Publications, Thousands Oaks

Dillenbourg P (1999) What do you mean by collaborative learning? In: Dillenbourg P (ed) Collaborative-learning: cognitive and computational approaches. Elsevier, Oxford 
Duncan K, Kenworthy A, McNamara R (2012) The effect of synchronous and asynchronous participation on students the learning power of participatory web sit. Account Educ 21(4):431-449

Edmonds CT, Edmonds TP (2010) An examination of the links between SRS technology and an active learning environment in a managerial accounting course. Adv Account Educ 11:81-100

Ellison N, Steinfield C, Lampe C. The benefits of Facebook "friends": exploring the relationship between college students' use of online social networks and social capital. J Comput Mediate Commun. 2007;12(3). http://jcmc.indiana.edu/ vol12/issue4/ellison.html

Fowler FJ, Mangione TW (1990) Standardized survey interviewing. Sage, Newbury Park

Gaffney MA, Ryan D, Wurst C (2010) Do online homework systems improve student performance? Adv Account Educ. 11:49-68

Geer JG (1988) What do open-ended questions measure? Pub Opin Quarter 52(3):365-367

Geer JG (1991) Do open-ended questions measure "salient" issues? Pub Opin Quarter 55(3):360-370

Ghauri P (2004) Designing and conducting case studies in international business research. In: Marschan-Piekkari R, Welch $C$ (eds) Handbook of qualitative research methods handbook of qualitative research methods for international business. Edward Elgar, Cheltenham

Greenwood DJ, Levin M (1998) Introduction to action research: social research for social change. SAGE Publications, Thousands Oaks

Groundwater-Smith S, Downes T. Students: from informants to co-researchers. Paper presented at the Australian Association of Research in Education Annual Conference, in Melbourne. 1999. http://www.aare.edu.au/99pap/gro99031. $\mathrm{htm}$. Accessed 27 May 2015

Heiberger G, Harper R (2008) Have you Facebook ed Astin lately? Using technology to increase student involvement. In: Junco R, Timm DM (eds) Using emerging technologies to enhance student engagement. Jossey-Bass, San Francisco

Hewitt A, Forte A (2006) Crossing boundaries: Identity management and student/faculty relationships on the Facebook, Poster presented at CSCW. CSCW, Banff

Hornik S, Thornburg S (2010) Really engaging accounting: second life ${ }^{\mathrm{TM}}$ as a learning platform. Issue Account Educ 25(3):361-378

Ismail S (2010) International students' acceptance on using social networking site to support learning activities. Int J Adv Sci Arts 1(2):81-90

Jones SH, Wright ME (2010) The effects of a hypertext learning aid and cognitive style on performance in advanced financial accounting. Issue Account Educ 25(1):35-58

Jong D, Wang TS (2009) Student acceptance of web-based learning system. Proceedings of the 2009 International Symposium on Web Information Systems and Applications (WISA'09) Nanchang, P.R. China, May 22-24, 2009. pp. $533-36$

Katz YJ (2000) The comparative suitability of three ICT distance learning methodologies for college level instruction. Educ Media Int 37(1):25-30

Katz YJ (2002) Attitudes affecting college students' preferences for distance learning. J Comput Assist Learn 18:2-9

Khanlarian C, Shough E, Singh R (2010) Student perceptions of web-based homework software: a longitudinal examination. Adv Account Educ 11:197-220

Kosik A (2007) The implications of Facebook. Sharing the commonwealth, Crit Issues Higher Educ, pp 9-10

Lee MKO, Cheung CMK, Chen Z (2005) Acceptance of Internet-based learning medium: the role of extrinsic and intrinsic motivation. Inform Manage 42(8):1095-1104

LinCS WuS, Tsai RJ (2005) Integrating perceived playfulness into expectation-confirmation model for web portal context. Inform Manag 42(5):683-693

Locke L (2007) The future of Facebook, time (July 17)

Lusher AL, Huber MM, Valencia JM (2012) Empirical evidence regarding the relationship between the computerized classroom and student performance in introductory accounting. Account Account Educ J 22:1-23

Madge C, Meek J, Wellens J, Hooley T (2009) Facebook, social integration and informal learning at university: "It is more for talking to friends about work than for actually doing work. Learn Media Technol 34:141-155

Maguire P (2001) Uneven ground: feminisms and action research. In: Reason P, Bradbury H (eds) Handbook of action research: participative inquiry and practice, 1st edn. SAGE Publications, London

Marchewka JT, Liu C, Kostiwa K (2007) An application of the UTAUT model for understanding student perceptions using course management software. Commun IIMA 7(2):93-104

Marriott N, Marriott P, Selwyn N (2004) Accounting undergraduates' changing use of ICT and their views on using the Internet in higher education-a research note. Account Educ 13(sup 1):117-130

Mason R (2006) Learning technologies for adult continuing education. Stud Continue Educ 28(2):121-133

Mason R (2011) Student engagement with, and participation in, an e-forum. Educ Technol Soc. 2011:258-268

Mazer JP, RE Simonds, Murphy CJ (2009) The effects of teacher self-disclosure via Facebook on teacher credibility. Learn Media Technol 34:175-183

Mazman SG, Usluel YK (2010) Modeling educational usage of Facebook. Comput Educ 55(2):444-453

McInnis C, James R, Hartley R (2000) Trends in the first year experience in Australian universities. AGPS, Canberra

Millson MR, Wilemon D (2008) Educational quality correlates of online graduate management education. J Distance Educ 22(3):1-18

Neibling J (2010) Speaking the language of today's digital natives. Commun Coll J 81(1):14-15

Pedersen AF. The construction of patient identities in the websites of patient associations, paper presented at 24th Egos Colloquium, Amsterdam, July. 2008

PempekTA, Yermolayeva YA, Calvert SL (2009) College students'social networking experiences on Facebook. J Appl Dev Psychol 30(3):227-238

Phillips F, Johnson BG (2011) Online homework versus intelligent tutoring systems: pedagogical support for transaction analysis and recording. Issue Account Educ 26(1):87-97

Potter BN, Johnston CG (2006) The effect of interactive on-line learning systems on student learning outcomes in accounting. J Account Educ 24(1):16-34 
Premuroso RF, Tong L, Beed TK (2011) Does using clickers in the classroom matter to student performance and satisfaction when taking the introductory financial accounting course? Issue Account Educ 26(4):701-723

Ramayah T, Ignatius J, Aafaqi B. PC usage among students: the case of a private institution of higher learning. The Proceedings of the International Conference on Management Education, Kuala Lumpur, Malaysia. 2004

Roca JC, Chiu CM, Martinez FJ (2006) Understanding e-learning continuance intention: an extension of the technology acceptance model. Int J Hum-Comput Stud 64(8):683-696

Rodgers T (2008) Student engagement in the e-learning process and the impact on their grades. Int J Cyber Soc Educ. 1(2):143-156

Ryan SH, Magro MJ, Sharp JK (2011) Exploring educational and cultural adaptation through social networking sites. J Inf Technol Educ 10:1-16

Sander P, Stevenson K, King M, Coates D (2000) University students' expectations of teaching. Stud High Educ 25(3):309-323

Sargent CS, Borthick AF, Lederberg AR (2011) Improving retention for principles of accounting students: ultra-short online tutorials for motivating effort and improving performance. Issue Account Educ 26(4):657-679

Segars AH, Grover V (1993) Re-examining perceived ease of use and usefulness: a confirmatory factor analysis. MIS Quarter 17(1):517-725

Selwyn N (2007) Web 2.0 applications as alternative environments for informal learning — a critical review. OECD CERIKERIS International expert meeting on ICT and educational performance. Organization for Economic Cooperation and Development, Cheju Island

Subrahmanyam K, Reich SM, Waechter N, Espinoza G (2008) Online and offline social networks: use of social networking sites by emerging adults. J Appl Dev Psychol 29(6):420-433

Šumak B, Pušnik M, Heričko M. Investigation of virtual learning environment in the context of web 2.0. Second International Conference on Mobile, Hybrid, and on-line learning. IEE Computer Society; 2010

Suwardy T, Pan G, Seow PS (2013) Using Digital Storytelling to Engage Student Learning. Account Educ 2(2):1-16

Tinto V, Love AG (1995) A longitudinal study of learning communities at LaGuardia community college. Office of Education Research and Improvement, Washington, DC

Trentin G (1997) Telematics and on-line teacher training: the POLARIS project. J Comput Assist Learn 13(4):261-270

Uden L, Eardley WA (2011) Knowledge sharing in the learning process: experience with problem-based learning. In: Uden L, Eardley WA (eds) Innovative knowledge management: concepts for organizational creativity and collaborative design. IGI Global Publications, Hershey

Van Der Vegt GS, Bunderson JS (2005) Learning and performance in multidisciplinary teams: the importance of collective team identification. Acad Manag J 48(3):532-547

Venkatesh V, Morris MG, Davis GB, Davis FD (2003) User acceptance of information technology toward a unified view. MIS Quarter. 27(3):425-478

Voss R, Gruber T, Szmigin I (2007) Service quality in higher education: the role of student expectations. J Bus Res 60(9):949-959

Wang Z, Tchernev JM, Solloway T (2012) A dynamic longitudinal examination of social media use, needs, and gratifications among college students. Comput Hum Behav 28(5):1829-1839

Webster J, Martocchio JJ (1992) Microcomputer playfulness: development of a measure with workplace implications. MIS Quarter 16:201-226

Wells P, De Lange P, Fieger P (2008) Integrating a virtual learning environment into a second-year accounting course: determinants of overall student perception. Account Finance 48(3):503-518

Wenger E (1998) Communities of Practice. Cambridge University Press, Cambridge

Wenger E (2000) Communities of practice and social learning systems. Organization 7(2):225-246

Williams KY, O'Reilly III CA (1998) A review of 40 years of research. Res Organ Behav 20:77-140

Woszczynski AB, Roth PL, Segars AH (2002) Exploring the theoretical foundations of playfulness in computer interactions. Comput Hum Behav 18(4):369-388

Yu AY, Tian SW, Vogel D, Chi-Wai K, Wok R (2010) Can learning be virtually boosted? An investigation of online social networking impacts. Comput Educ 55(4):1494-1503

\section{Submit your manuscript to a SpringerOpen ${ }^{\circ}$ journal and benefit from:}

- Convenient online submission

- Rigorous peer review

- Immediate publication on acceptance

Open access: articles freely available online

- High visibility within the field

- Retaining the copyright to your article

Submit your next manuscript at $\gg$ springeropen.com 